\title{
Red Fluorescent 4-(Dicyanomethylene)-2-norbonenyl-6-(1,1,7,7-tetramethyljulolidyl- 9-enyl)-4H-pyran (DCJNB) for Organic Light-Emitting Diodes (OLEDs)
}

\author{
Kum Hee Lee, Young Kwan Kim, ${ }^{\dagger, *}$ and Seung Soo Yoon ${ }^{*}$ \\ Department of Chemistry, Sungkyunkwan University, Suwon 440-746, Korea. *E-mail: ssyoon@skku.edu \\ †Department of Information Display, Hongik University, Seoul 121-791, Korea. *E-mail: kimyk@hongik.ac.kr \\ Received December 17, 2010, Accepted February 19, 2011
}

Key Words : Red fluorescence, OLED, Pyran derivative, Norbonenyl group

The development of the emitting materials for organic light-emitting diodes (OLEDs) have received considerable attention due to their potential application in flat panel displays and solid-state lighting. ${ }^{1-6}$ However, red fluorescent emitting materials remains one of the greatest challenges for the practical application of OLEDs. ${ }^{7-9}$ Although a variety of red fluorescent materials including the pyran containing materials such as 4-(dicyanomethylene)-2-methyl-6-[ $p$-(dimethylamino)styryl]-4H-pyran) (DCM) and 4-(dicyanomethylene)-2-tert-butyl-6-(1,1,7,7-tetramethyljulolidyl-9-enyl)$4 H$-pyran (DCJTB), ${ }^{10,11}$ the arylamino-polyaromatic hydrocarbon derivatives, ${ }^{12}$ polyacenes ${ }^{13}$ and metal chelates ${ }^{14}$ have been widely studied, their EL performances are not pleased with a prerequisite for the practical applications.

Up to now, DCJTB derivatives have been extensively studied. For examples, W. Zhu's group reported a new DCJTB derivative such as 4-(dicyanomethylene)-2-tert-butyl-6-(8(4-methyl)phenyl-2,3-dihydro- $1 H$-cyclopenta [3a,8a]indolin5 -enyl)- $4 H$-pyran (DCINB) which showed the red electroluminescence with the luminance and power efficiencies of 1.8 and 4.6 times higher than those of DCJTB. ${ }^{15}$ Also, Y. -S. Yao et al. published a new DCJTB derivative such as 4- (dicyanomethylene)-2-tert-butyl-6-(2-(2,6,6-trimethyl-2,4,5,6tetrahydro- $1 H$-pyrrolo[3,2,1-ij]quinolin-8-enyl))-4H-pyran (DCQTB) which showed the red electroluminescence with the luminance and luminous efficiencies of 1.5 times higher than that of DCJTB. ${ }^{16}$ In these materials, the bulky substituents based on indolidine are incorporated into skeleton of DCJTB to prevent concentration quenching between the emitting materials, which lead to the improved EL efficiencies of devices using them. ${ }^{16}$ However, their EL performances still need to be improved.

In this paper, we describe the synthesis and electroluminescent properties of a red fluorescent material, 4-dicyanomethylene-2-norbonenyl-6-(1,1,7,7-tetramethyljulolidyl-9enyl)-4H-pyran (DCJNB). In red emitter DCJNB, the bulky norbonenyl group is introduced into pyran moiety of DCJTB skeleton to increase steric hindrance between red emitters in the emitting layer of devices and thus improve the EL performances by preventing concentration quenching.

Structures and synthetic scheme of DCJNB and DCJTB were shown in Scheme 1. Synthesis of the red emitter DCJNB began with the preparation of the 2-methyl-6norbonenyl-4-(dicyanomethylene)- $4 H$-pyran by following

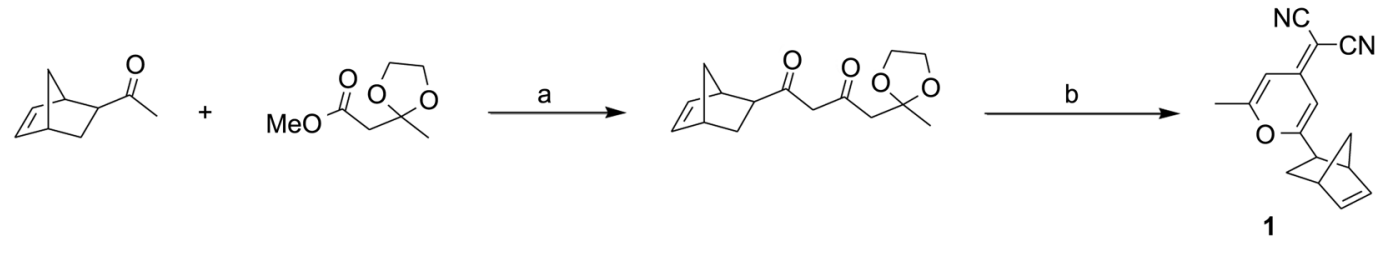<smiles>CC1(C)CCN2CCC(C)(C)c3cc(C=O)cc1c32</smiles><smiles></smiles>
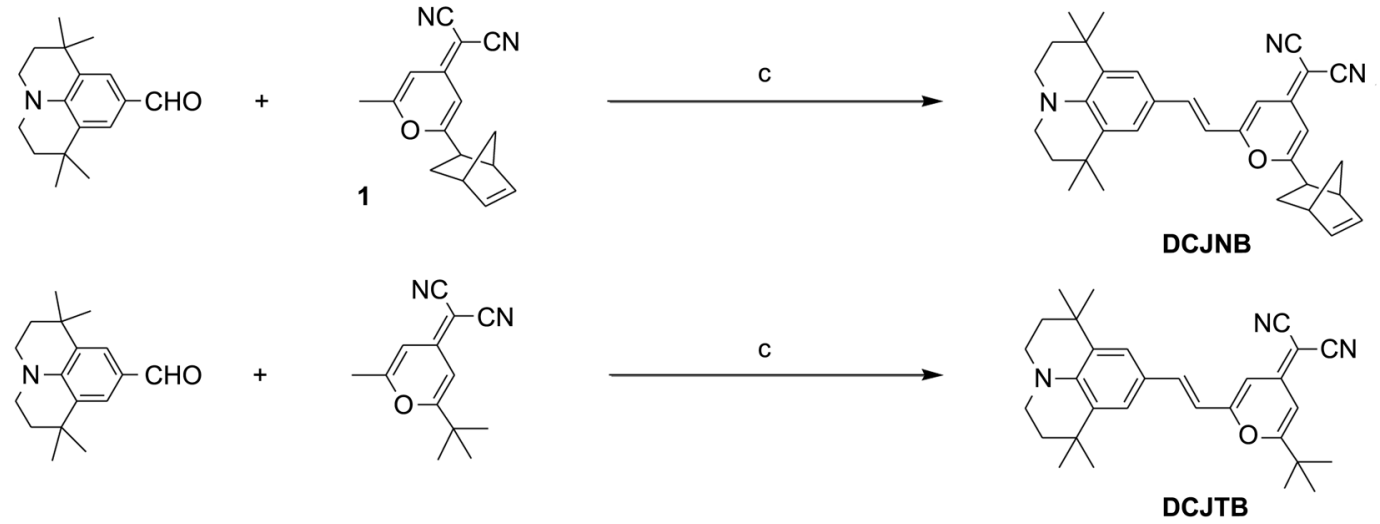

Scheme 1. Synthesis and structures of the red materials DCJNB and DCJTB. (a) NaN(TMS $)_{2}$. (b) i. $\mathrm{H}_{2} \mathrm{SO}_{4}$, ii. $\mathrm{CH}_{2}(\mathrm{CN})_{2}$. (c) Piperidine, EtOH. 


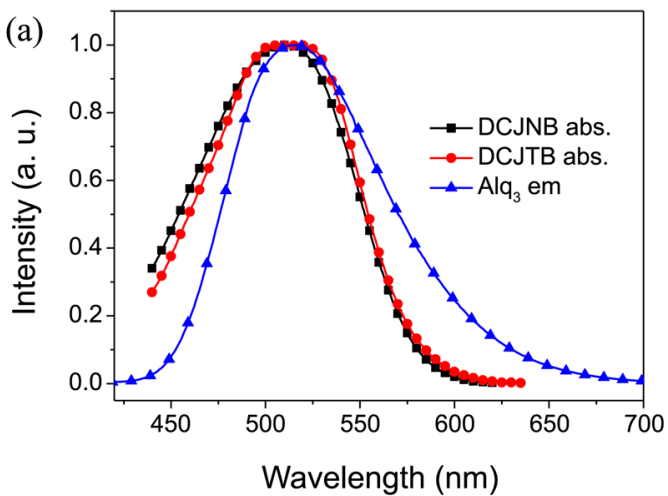

(b)

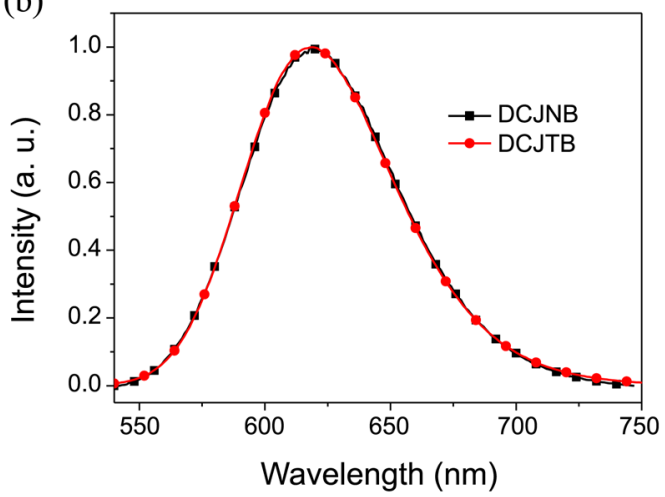

Figure 1. (a) UV-vis spectra and (b) PL spectra of red emitters DCJNB and DCJTB.

the known procedure. ${ }^{17}$ Subsequently, Knoevenagel condensation ${ }^{18}$ between 2-methyl-6-norbonenyl-4-(dicyanomethylene)-4H-pyran and 1,1,7,7-tetramethyljulolidylcarboaldehyde provided the red emitter DCJNB with the moderate yield. DCJTB was prepared by following the standard procedure. ${ }^{19}$ These compounds were fully characterized with ${ }^{1} \mathrm{H}$ NMR, low- and high-resolution mass spectrometry.

The ultraviolet-visible (UV-vis) absorption spectra of DCJNB and DCJTB are shown in Figure 1(a). The maximum absorption peaks of these materials were 510 and $511 \mathrm{~nm}$, respectively. Figure 1(a) shows the good overlap between the emission spectra of a common fluorescent red host material $\mathrm{Alq}_{3}$ and the absorption spectra of DCJNB and DCJTB. This observation imply that the Förster singlet energy transfer from host $\mathrm{Alq}_{3}$ to red emitter DCJNB and DCJTB would be efficient, and $\mathrm{Alq}_{3}$ served well as a host in the OLEDs by using these compounds as red dopant materials. Red emitters DCJNB and DCJTB exhibit efficient red emissions with maximum emission peaks of 618 and $619 \mathrm{~nm}$, respectively, as shown in Figure 1(b). The quantum yields of DCJNB and DCJTB were 0.82 and 0.78, respectively. The HOMO/LUMO levels for DCJNB and DCJTB were $-5.17 /-3.01 \mathrm{eV}$ and $-5.26 /-3.10 \mathrm{eV}$, respectively. All physical properties were shown in Table 1.

To explore the electroluminescent properties of DCJNB, OLED devices using DCJNB as a dopant in $\mathrm{Alq}_{3}$ host were fabricated. NPB, $\mathrm{Alq}_{3}$, and Liq were used for hole transporting layer, red host and electron transporting layer, and electron injection layer, respectively. Particularly, to optimize
Table 1. Physical properties of red emitters DCJNB and DCJTB

\begin{tabular}{lcccccc}
\hline Compound & $\begin{array}{c}\lambda_{\max }{ }^{a} \\
(\mathrm{~nm})\end{array}$ & $\begin{array}{c}\lambda_{\max }{ }^{b} \\
(\mathrm{~nm})\end{array}$ & $\begin{array}{c}\text { FWHM } \\
(\mathrm{nm})\end{array}$ & $\begin{array}{c}\text { HOMO/LUMO } \\
(\mathrm{eV})\end{array}$ & $\mathrm{E}_{\mathrm{g}}$ & $\Phi^{c}$ \\
\hline DCJNB & 510 & 618 & 71 & $-5.17 /-3.01$ & 2.16 & 0.82 \\
DCJTB & 511 & 619 & 72 & $-5.26 /-3.10$ & 2.16 & 0.78 \\
\hline
\end{tabular}

${ }^{a}$ Maximum absorption or emission wavelength in 1,2-dichloroethane (ca. $\left.1 \times 10^{-5} \mathrm{M}\right) .{ }^{b}$ Obtained from AC-2 and UV-vis absorption measurements. ${ }^{c}$ Fluorescent quantum yields were determined in 1,2-dichloroethane at $293 \mathrm{~K}$ against $\mathbf{D C J T B}(\Phi=0.78){ }^{20}$

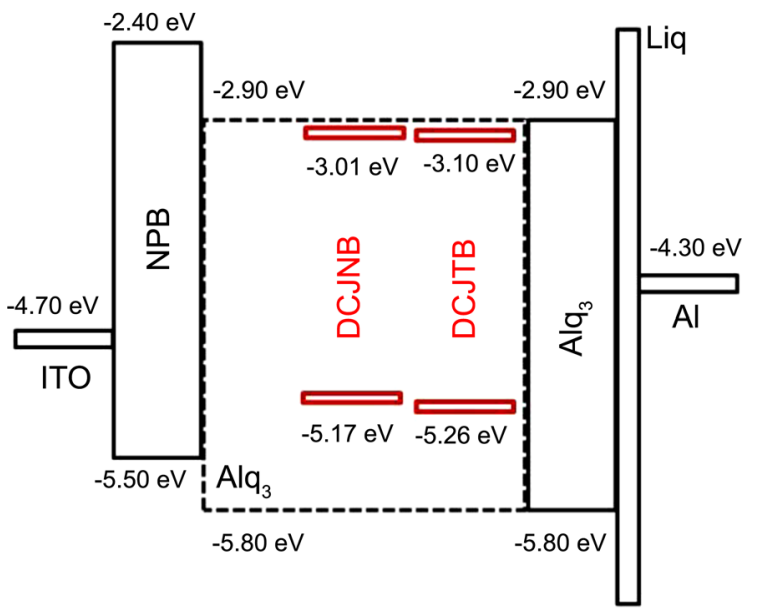

Figure 2. Structure and Energy-level diagram of device using DCJNB and DCJTB as dopants.

the device structure, three kinds of devices with the different doping concentrations such as 1,5 and $10 \%$ were fabricated. Also, for the comparison, the control device using DCJTB as a dopant in $\mathrm{Alq}_{3}$ host at $1 \%$ doping concentration was fabricated.

All electroluminescent data on devices using DCJNB and DCJTB was summarized in Table 2. The luminous and power efficiencies of devices are shown in Figure 3. Also, the EL spectra of devices are shown in Figure 4. The maximum luminous efficiency of devices $\mathbf{1}$ and $\mathbf{4}$ using DCJNB and DCJTB as dopants at the same doping concentration were 3.73 and $2.52 \mathrm{~cd} / \mathrm{A}$, respectively. The luminous efficiency of devices $\mathbf{1}$ and $\mathbf{4}$ using DCJNB and

Table 2. EL performance characteristic of devices DCJNB and DCJTB

\begin{tabular}{ccccccc}
\hline Device & $\begin{array}{c}\text { Dopant } \\
(\%)^{a}\end{array}$ & $\begin{array}{c}\mathrm{L}^{b} \\
\left(\mathrm{~cd} / \mathrm{m}^{2}\right)\end{array}$ & $\begin{array}{c}\mathrm{LE}^{c / d} \\
(\mathrm{~cd} / \mathrm{A})\end{array}$ & $\begin{array}{c}\mathrm{PE}^{c / d} \\
(\mathrm{~lm} / \mathrm{W})\end{array}$ & $\begin{array}{c}\mathrm{EL} \\
(\mathrm{nm})\end{array}$ & $\begin{array}{c}\mathrm{CIE}^{e} \\
(\mathrm{x}, \mathrm{y})\end{array}$ \\
\hline $\mathbf{1}$ & $\begin{array}{c}\text { DCJNB } \\
(1.0)\end{array}$ & 9740 & $3.73 / 3.01$ & $2.17 / 0.90$ & 610 & $(0.58,0.40)$ \\
$\mathbf{2}$ & $\begin{array}{c}\text { DCJNB } \\
(5.0)\end{array}$ & 1720 & $0.62 / 0.49$ & $0.25 / 0.14$ & 634 & $(0.64,0.35)$ \\
$\mathbf{3}$ & $\begin{array}{c}\text { DCJNB } \\
(10.0)\end{array}$ & 608 & $0.40 / 0.32$ & $0.18 / 0.05$ & 638 & $(0.64,0.36)$ \\
$\mathbf{4}$ & $\begin{array}{c}\text { DCJTB } \\
(1.0)\end{array}$ & 6300 & $2.52 / 2.38$ & $1.32 / 1.08$ & 616 & $(0.60,0.39)$ \\
& & & & & \\
\hline
\end{tabular}

${ }^{a}$ Doping concentration. ${ }^{b}$ Maximum luminance. ${ }^{c}$ Maximum value. ${ }^{d}$ At 20 $\mathrm{mA} / \mathrm{cm}^{2}$. ${ }^{e}$ Commission Internationale d'Énclairage (CIE) coordinates at a $7.0 \mathrm{~V}$. 
DCJTB as dopants at the same doping concentration were 3.10 and $2.38 \mathrm{~cd} / \mathrm{A}$ at $20 \mathrm{~mA} / \mathrm{cm}^{2}$, respectively. And the maximum power efficiency of devices 1 and 4 were 2.17 and $1.32 \mathrm{~lm} / \mathrm{W}$, respectively. Notably, compared to device 4 using DCJTB, the maximum luminous and power efficiency of device 1 using DCJNB increased by 48 and 64\%, respectively. The bulky norbonenyl group of dopant DCJNB of device 1 could prevent molecular aggregation and thus reduce concentration quenching. This would contribute to the improved luminous efficiency of device $1 .^{21,22}$ However, the other factors such as the higher quantum yield of DCJNB (0.82) than that of DCJTB (0.78), and the effective hole-trapping into DCJNB in device $\mathbf{1}$ due to the higher HOMO energy level of DCJNB $(-5.17 \mathrm{eV})$ than that of DCJTB $(-5.26 \mathrm{eV})$ could contribute to the improved EL efficiencies of device 1 in comparison to device $4 .^{16}$

In devices 1, 2 and 3 using DCJNB as a dopant at the different doping concentrations, with the increase of doping concentration from $1 \%$ to 5 and $10 \%$, the luminous and power efficiencies decreased due to the concentration quenching effect. Interestingly, the EL spectra of device 1 showed $\mathrm{Alq}_{3}$ emission around $510 \mathrm{~nm}$ due to the incomplete energy transfer from $\mathrm{Alq}_{3}$ host to dopant DCJNB in the emitting layer. However, the EL spectra of devices $\mathbf{2}$ and $\mathbf{3}$ showed no $\mathrm{Alq}_{3}$ emission by the efficient exciton formation at dopant DCJNB with the increase of doping concentrations. Notably, the EL spectra of device 1, 2 and $\mathbf{3}$ showed the shoulder peak around $670 \mathrm{~nm}$ and their intensity increased upon the change of doping concentration from 1 to
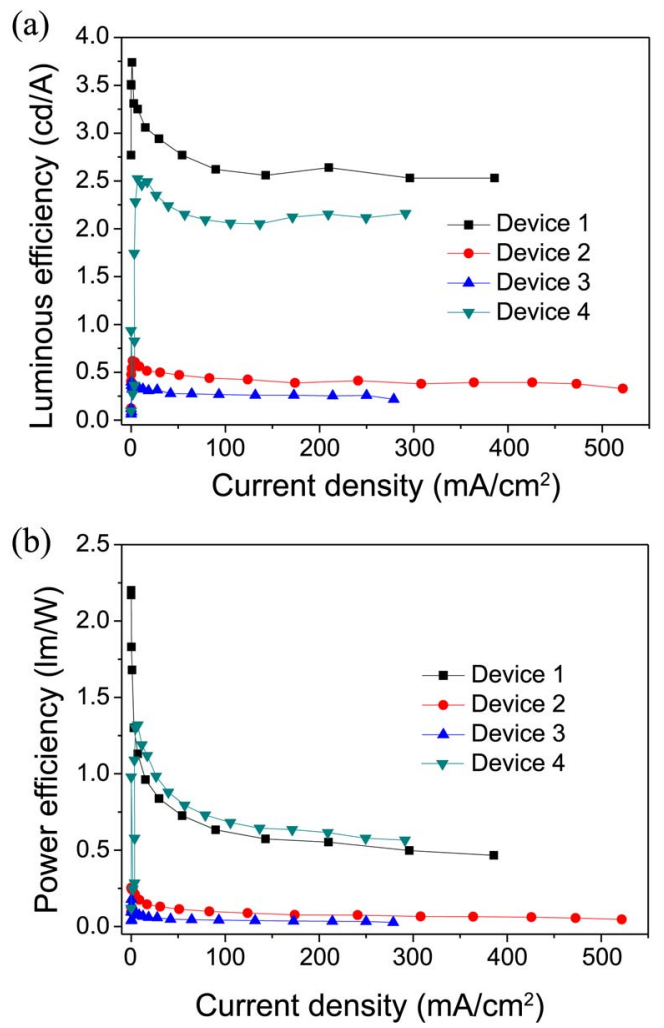

Figure 3. (a) Luminous efficiencies-current density and (b) power efficiencies-current density characteristics of devices 1-4.

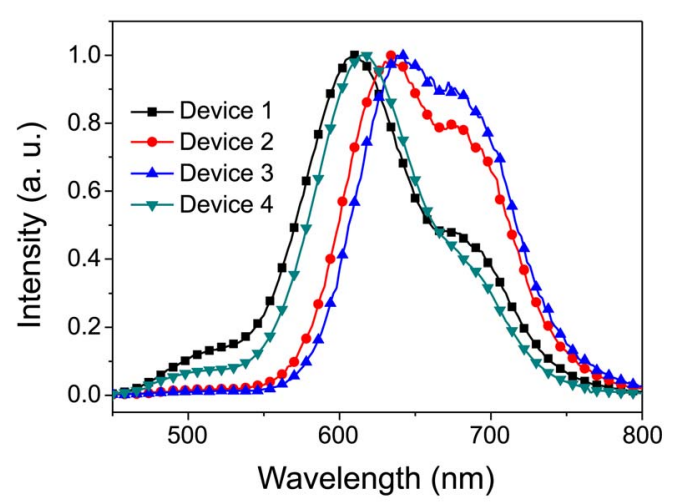

Figure 4. EL spectra the devices 1-4.

5 and $10 \%$. These observations imply that the emission peak around $670 \mathrm{~nm}$ might originate from the excimers of dopant DCJNB and the extent of excimer formation of dopant increased at the higher doping concentration.

The CIE coordinates of device 1 is $(0.58,0.40)$ in the orange-red region. Interestingly, compared to device $\mathbf{1}$, device 2 and 3 had the improved CIE coordinates of $(0.64,0.35)$ and $(0.64,0.36)$ at $7.0 \mathrm{~V}$, approaching saturated red emission due to the excimer formation of DCJNB. Although an efficient orange-red OLED using DCJNB has insufficient color purity for applications to full-color displays, DCJNB can be used to fabricate efficient white organic light-emitting diodes (WOLEDs). Recently, highly efficient WOLEDs by a combination of fluorescent sky-blue and red emitters with complementary colors has been demonstrated. ${ }^{23}$ Therefore, DCJNB is an excellent fluorescent red material for efficient WOLEDs with a combination of suitable sky blue emitters. ${ }^{24,25}$

In conclusion, we designed and synthesized a new red emitter DCJNB. A device with the structure of ITO/NPB $(50 \mathrm{~nm}) / \mathrm{Alq}_{3}: \mathbf{D C J N B}(1 \%)(30 \mathrm{~nm}) / \mathrm{Alq}_{3}(40 \mathrm{~nm}) / \mathrm{Liq}(2$ $\mathrm{nm}) / \mathrm{Al}$ showed the luminous and power efficiencies of 3.01 $\mathrm{cd} / \mathrm{A}$ and $0.90 \mathrm{~lm} / \mathrm{W}$ at $20 \mathrm{~mA} / \mathrm{cm}^{2}$, respectively. The CIE coordinates of this device was $(0.58,0.40)$ at $7.0 \mathrm{~V}$. Compared to a device using DCJTB, this device showed the improved EL performances due to reducing the molecular aggregation and thus preventing concentration quenching. This study demonstrates that a DCJTB derivative, DCJNB possesses excellent properties for efficient red fluorescent OLEDs as well as white OLEDs.

\section{Experimental Section}

Materials and Measurement. The UV-vis absorption and photoluminescence spectra of these newly designed red dopants were measured in a $10^{-5} \mathrm{M}$ solution of 1,2-dichloroethane. Fluorescent quantum yields were determined in 1.2dichloroethane at $293 \mathrm{~K}$ against DCJTB $=0.78 .{ }^{12}$ The HOMO energy levels were measured with low energy photo-electron spectrometry (Riken-Keiki AC-2). The LUMO energy levels were estimated by subtracting the energy gap from the HOMO energy levels.

Synthesis of 1 (4-dicyanomethylene-2-norbonenyl-6methyl-4H-pyran). To a solution of $1.0 \mathrm{~g}$ of 5 -acetyl-2- 
norbonene $(14.68 \mathrm{mmol})$ in $30 \mathrm{~mL}$ of $\mathrm{THF}$ at $-78{ }^{\circ} \mathrm{C}$ was added $36.71 \mathrm{~mL}$ of $1 \mathrm{M} \mathrm{NaN}(\mathrm{TMS})_{2}$ solution in THF. After stirring $1 \mathrm{hr}$ at $-78{ }^{\circ} \mathrm{C}, 4.7 \mathrm{~g}$ of methyl 2-(2-methyl-1,3dioxolan-2-yl)acetate $(29.37 \mathrm{mmol})$ was added and then heated to $70{ }^{\circ} \mathrm{C}$ for $12 \mathrm{hr}$. The reaction mixture was quenched with $\mathrm{NH}_{4} \mathrm{Cl}$ aqueous solution and then extracted with ethyl acetate. After the evaporation of ethyl acetate, column chromatography using silica gel with the elution of ethyl acetate and hexane provided $1.7 \mathrm{~g}$ of the crude 1-(bicycle[2,2,1]hept-5-en-2-yl)-4-(2-methyl-1,3-dioxolan-2-yl)butane-1,3-dione (6.86 mmol, 46.72\%). This crude compound was dissolved in $10 \mathrm{~mL}$ of $95 \% \mathrm{H}_{2} \mathrm{SO}_{4}$ solution and then stirred for $4 \mathrm{hr}$ at room temperature. After the neutralization with $\mathrm{NaHCO}_{3}$ solution, the reaction mixture was extracted with ethyl acetate. Without further purification, the crude products were dissolved in $6 \mathrm{~mL}$ of acetylanhydride and then $0.16 \mathrm{~g}$ of malononitrile $(2.47 \mathrm{mmol})$ was added to the reaction mixture. After refluxing the reaction mixture for 12 $\mathrm{hr}$, the crude products were extracted with ethyl acetate. Column chromatography using silica gel with the elution of ethyl acetate and hexane provided $1.01 \mathrm{~g}$ of 1 (4.01 mmol, 58.34\%). ${ }^{1} \mathrm{H}-\mathrm{NMR}\left(300 \mathrm{MHz}, \mathrm{CDCl}_{3}\right) \delta(\mathrm{ppm}) 6.15(\mathrm{~m}$, $1 \mathrm{H}), 5.72(\mathrm{~m}, 1 \mathrm{H}), 5.21(\mathrm{~m}, 1 \mathrm{H}), 5.16(\mathrm{~m}, 1 \mathrm{H}), 2.31(\mathrm{~m}, 2 \mathrm{H})$, $2.12(\mathrm{~m}, 1 \mathrm{H}), 1.97(\mathrm{~m}, 1 \mathrm{H}), 1.74(\mathrm{~s}, 3 \mathrm{H}), 1.66(\mathrm{~m}, 1 \mathrm{H}), 1.59$ $(\mathrm{m}, 1 \mathrm{H}), 1.30(\mathrm{~m}, 1 \mathrm{H})$; FT-IR $(\mathrm{KBr}) \vee 2931,2311,1592$, $1522,835 \mathrm{~cm}^{-1}$; Mass (EI) $m / z=250\left(\mathrm{M}^{+}\right)$.

Synthesis of 4-Dicyanomethylene-2-norbonenyl-6-(1,1,7,7tetramethyljulolidyl-9-enyl)-4H-pyran (DCJNB). To a solution of $0.273 \mathrm{~g}$ of $1(1.09 \mathrm{mmol})$ and $0.28 \mathrm{~g}$ of $1,1,7,7-$ tetramethyljulolidine carboaldehyde $(1.09 \mathrm{mmol})$ in $20 \mathrm{~mL}$ of $\mathrm{EtOH}$ was added $0.43 \mathrm{~mL}$ of piperidine $(4.36 \mathrm{mmol})$ at room temperature. After refluxing under deanstark trap for 5 $\mathrm{h}$, the resulting crude solid products was filtered and then washed with brine. Recrystallized with ethyl alcohol provided $73 \mathrm{mg}$ of DCJNB as reddish solids $(0.149 \mathrm{mmol}, 13.7 \%)$. ${ }^{1} \mathrm{H}-\mathrm{NMR}\left(300 \mathrm{MHz}, \mathrm{CDCl}_{3}\right) \delta(\mathrm{ppm}) 7.01(\mathrm{~m}, 2 \mathrm{H}), 6.77(\mathrm{~m}$, $1 \mathrm{H}), 6.54(\mathrm{~m}, 1 \mathrm{H}), 6.21(\mathrm{~m}, 1 \mathrm{H}), 5.69(\mathrm{~m}, 1 \mathrm{H}), 5.20(\mathrm{~m}, 1 \mathrm{H})$, $5.11(\mathrm{~m}, 1 \mathrm{H}), 3.37(\mathrm{~m}, 4 \mathrm{H}), 2.52(\mathrm{~m}, 2 \mathrm{H}), 2.10(\mathrm{~m}, 1 \mathrm{H}), 1.92$ $(\mathrm{m}, 1 \mathrm{H}), 1.75(\mathrm{~m}, 4 \mathrm{H}), 1.65(\mathrm{~m}, 1 \mathrm{H}), 1.58(\mathrm{~m}, 1 \mathrm{H}), 1.42(\mathrm{~m}$, $12 \mathrm{H}), 1.31(\mathrm{~m}, 1 \mathrm{H})$; FT-IR $(\mathrm{KBr}) \vee 2987,2321,1579,1561$, $1501 \mathrm{~cm}^{-1}$; Mass (EI) $\mathrm{m} / z=489\left(\mathrm{M}^{+}\right)$; HRMS (EI) calcd for $\mathrm{C}_{33} \mathrm{H}_{35} \mathrm{~N}_{3} \mathrm{O}$, 489.2780; found, 489.2772; mp $214{ }^{\circ} \mathrm{C}$.

Device Fabrication and Characterization. OLEDs using red-light-emitting molecules were fabricated by vacuum $\left(10^{-6}\right.$ torr) thermal evaporation onto pre-cleaned ITO coated glass substrates. The indium tin oxide (ITO) was first cleaned with acetone, methyl alcohol, distilled water, and kept in isopropyl alcohol for $48 \mathrm{~h}$ and dried by $\mathrm{N}_{2}$ gas. The device structures were as follows: (1) ITO/ $N, N^{\prime}$-diphenyl- $N, N^{\prime}-(1-$ napthyl)-(1,1'-biphenyl)-4,4'-diamine (NPB) (40 nm)/tris (8quionlinolato)-aluminium $\left(\mathrm{Alq}_{3}\right)$ : Red dopant (x \%) (20 nm) $/ \mathrm{Alq}_{3}(40 \mathrm{~nm}) / \mathrm{Liq}(2 \mathrm{~nm}) / \mathrm{Al}$. All of the properties of the OLEDs such as the current density (J), luminance (L), luminance efficiency (LE), power efficiency (PE), and commission international de l'Éclairage (CIE) coordinate characteristics were measured using a Keithly 2400 source measurement unit and a Chroma meter MINOLTA CS1000A. Electro-luminance was measured using a Roper Scientific Pro 300i.

Acknowledgments. This research was supported by Basic Science Research Program through the National Research Foundation of Korea (NRF) funded by the Ministry of Education, Science and Technology (20100007370).

\section{References and Notes}

1. Tang, C. W.; VanSlyke, S. A. Appl. Phys. Lett. 1987, $51,913$.

2. Organic Light-Emitting Materials and Devices; Li, Z., Meng, H. Eds.; Taylor \& Francis: Boca Raton, U. S. A. 2007; p 295.

3. Lee, K. H.; Kwon, Y. S.; Kang, L. K.; Kim, G. Y.; Seo, J. H.; Kim, Y. K.; Yoon, S. S. Synth. Met. 2009, 159, 2603.

4. Kwon, Y. S.; Lee, K. H.; Kim, G. Y.; Seo, J. H.; Kim, Y. K.; Yoon, S. S. J. Nanosci. Nanotechnol. 2009, 9, 7056.

5. Kim, S. O.; Lee, K. H.; Kang, S.; Lee, J. Y.; Seo, J. H.; Kim, Y. K.; Yoon, S. S. Bull. Korean Chem. Soc. 2010, 31, 389.

6. Lee, K. H.; Seo, J. H.; Kim, Y. K.; Yoon, S. S. J. Nanosci. Nanotechnol. 2009, 9, 7099.

7. Chen, C. Chem. Mater. 2004, 16, 4389

8. Lee, K. H.; Kim, S. M.; Kim, J. Y.; Kim, Y. K.; Yoon, S. S. Bull. Korean. Chem. Soc. 2010, 31, 2884.

9. Lee, K. H.; Park, M. H.; Kim, S. M.; Kim, Y. K.; Yoon, S. S. Jpn. J. Appl. Phys. 2010, 49, 08JG02.

10. Chen, C. H.; Tang, C. W.; Shi, J., Klubek, K. P. Thin Solid Films 2000, 363, 327.

11. Tang, C. W.; Van Slyke, S. A.; Chen, C. H. J. Appl. Phys. 1989, 65,3610 .

12. Thomas, K. J. R.; Lin, J. T.; Tao, Y.; Chuen, C. Adv. Func. Mater. 2004, 14, 822 .

13. Picciolo, L. C.; Murata, H.; Kafati, Z. H. Appl. Phys. Lett. 2001, 78, 2378.

14. Fang, J.; Ma, D. Appl. Phys. Lett. 2003, 83, 4041.

15. Zhao, P.; Tang, H.; Zhang, Q.; Pi, Y.; Xu, M.; Sun, R.; Zhu, W. Dyes and Pigments 2009, 82, 316.

16. Yao, Y.-S.; Zhou, Q.-X.; Wang, X.-S.; Wang, Y.; Zhang, B.-W. Adv. Func. Mater. 2007, 17, 93.

17. Kim, B.-O.; Kim, C.-S.; Han H.; Kim S.-M.; Kim, J.-Y.; Cho, K.S.; Jung, S.-Y.; Yun, S. S.; Kwon, H.-J.; Cho, Y.-J.; Kim, Y. K.; Kim, S.-M. WO $121274(2005)$.

18. Jones, G. Org. React. 1967, 15, 204.

19. Chen, C. H.; Tang, C. W.; Shi, J. US 5935720 (1999).

20. Chen, C. H.; Tang, C. W.; Shi, J.; Klubek, K. P. Macromol. Symp. 1998, 125,49

21. Kido, J.; Hayase, H.; Hongawa, K. Appl. Phys. Lett. 1994, 65, 2124.

22. Lee, K. H.; Park, M. H.; Kim, J. Y.; Kim, S. M.; Seo, B. M.; Seo, J. H.; Kim, Y. K.; Yoon, S. S. J. Nanosci. Nanotechnol. 2011, 11, 1484.

23. Seo, J. H.; Park, J. S.; Kim, J. H.; Lee, K. H.; Kim, J. Y.; Yoon, S. S.; Kim, Y. K. Mol. Cryst. Liq. Cryst. 2010, 520, 83.

24. Kim, S. O.; Lee, K. H.; Kang, S.; Lee, J. Y.; Seo, J. H.; Kim, Y. K.; Yoon, S. S. Bull. Korean Chem. Soc. 2010, 31, 389.

25. Lee, K. H.; Kang, L. K.; Lee, J. Y.; Kang, S.; Jeon, S. O.; Yook, K. S.; Lee, J. Y.; Yoon, S. S. Adv. Func. Mater. 2010, 20, 1345. 